\title{
Surgeon experience impacts type A aortic dissection patient mortality
}

\author{
Meghan O. Kelly, Spencer J. Melby \\ Division of Cardiothoracic Surgery, Washington University School of Medicine, St. Louis, MO 63110, USA \\ Correspondence to: Meghan Kelly. Department of Surgery, Washington University School of Medicine, 660 S Euclid Ave, Campus Box 8109, St. Louis, \\ MO 63110, USA. Email: m.kelly@wustl.edu. \\ Provenance and Peer Review: This article was commissioned and reviewed by the Guest Section Editor Dr. Jian-cang Zhou (Department of Critical \\ Care Medicine, Sir Run Run Shaw Hospital, Zhejiang University School of Medicine, Hangzhou, China). \\ Comment on: Umana-Pizano JB, Nissen AP, Sandhu HK, et al. Acute Type A Dissection Repair by High-Volume vs. Low-Volume Surgeons at a \\ High-Volume Aortic Center. Ann Thorac Surg 2019;108:1330-6.
}

Submitted Jan 15, 2020. Accepted for publication Jan 30, 2020.

doi: $10.21037 /$ jtd.2020.02.03

View this article at: http://dx.doi.org/10.21037/jtd.2020.02.03

Patient outcomes following acute type A dissection repair have previously been shown to be better at high-volume centers. It is uncertain whether improved outcomes are associated with greater surgeon experience or resources accessible at high-volume centers; this is the question Umana-Pizano and colleagues pursued (1). They compared high versus low-volume surgeons at a high-volume aortic center to test the hypothesis that better outcomes following acute type A dissection repair may be primarily associated with surgeon experience and not with resources found at high-volume centers. They defined high-volume aortic surgeons (HVAS) as those who performed over ten cases per year. They found that the best outcomes were when an HVAS was the team leader (mortality 14.7\%). Even when an HVAS was a secondary surgeon, mortality was higher $(17.6 \%)$. The worst outcomes were in a team with two lowvolume surgeons (mortality 24\%), although numbers were too low to reach statistical significance.

A similar study by Bashir, which analyzed surgeon experience on outcome for all acute type A aortic dissections in the national UK database, had similar results: lowvolume surgeons performing acute type A aortic dissection repair had significantly higher in-hospital mortality when compared to high-volume surgeons $(19.3 \%$ vs. $12.6 \%$, $\mathrm{P}=0.015)$. In that study, surgeon experience was defined with a much lower cutoff: only four cases qualified a surgeon as "high-volume" (2).

Several studies have shown, unsurprisingly, that outcomes were better for acute type A aortic dissection repair in highvolume centers. For example, in a hospital that does a mean 22.3 operations/year, the mortality was $14.1 \%$ compared to low-volume centers (mean 1.1 operations/year) in which operative mortality was $24.1 \%, \mathrm{P}=0.001$ (3). Most would agree that better outcomes can be obtained in higher volume centers and with more experienced surgeons.

Patients who suffer type A aortic dissection have exceptionally high mortality and require rapid and often complex surgical intervention as well as demanding periand post-operative care. This study asks the question whether the surgeon's expertise may play a critical role in outcomes of these patients. In general, most surgeons would agree that specialization in any technique (e.g., performing one type of surgery often) leads to better outcomes. However, this argument is typically followed with some push towards having patients with that specific disease transferred to the more experienced centers and surgeons. There are some potential pitfalls to this thinking in this disease.

First, transfer of every patient to a "high-volume center" or to more experienced surgeons always takes timeand these critically ill patients can die in the hour or two (or more) it takes to transfer them. There are no trials that show better survival in those being transferred; but if roughly $10 \%$ of patients die in every hour of delay, it quickly becomes imperative that a patient receive surgery sooner. Some patients may be "stable" for transfer, but some 
(with malperfusion) may not.

Second, partners may become disgruntled as this emergency case (one of the few remaining in CT surgery) is never convenient and often at night. Practically speaking, the more senior surgeons are going to be the "more experienced surgeons," but they may not want all the emergency cases.

Finally, younger inexperienced surgeons can only become more experienced by doing more cases.

In theory, most people would agree that the best, most experienced surgeons at the most experienced centers should perform these operations. This study supports that surgeons who do more of these cases have better outcomes. However, sending all patients with type A dissection to a more experienced surgeon does not address the problem of transfer time and potentially higher mortality of patients during prolonged transfers. Nor does reserving these cases for the most experienced surgeons allow for appropriate training of younger cardiac surgeons. Ultimately, some appropriate balance between training, transfer time, and equitable distribution of this difficult, usually inconvenient, high mortality case needs to be reached.

\section{Acknowledgments}

Funding: None.

\section{Footnote}

Conflicts of Interest: Both authors have completed the ICMJE uniform disclosure form (available at http://dx.doi. org/10.21037/jtd.2020.02.03). The authors have no conflicts of interest to declare.

Ethical Statement: The authors are accountable for all aspects of the work in ensuring that questions related to the accuracy or integrity of any part of the work are appropriately investigated and resolved.

Open Access Statement: This is an Open Access article distributed in accordance with the Creative Commons Attribution-NonCommercial-NoDerivs 4.0 International License (CC BY-NC-ND 4.0), which permits the noncommercial replication and distribution of the article with the strict proviso that no changes or edits are made and the original work is properly cited (including links to both the formal publication through the relevant DOI and the license). See: https://creativecommons.org/licenses/by-nc-nd/4.0/.

\section{References}

1. Umana-Pizano JB, Nissen AP, Sandhu HK, et al. Acute Type A Dissection Repair by High-Volume vs. LowVolume Surgeons at a High-Volume Aortic Center. Ann Thorac Surg 2019;108:1330-6.

2. Bashir M, Harky A, Fok M, et al. Acute type A aortic dissection in the United Kingdom: Surgeon volume-outcome relation. J Thorac Cardiovasc Surg 2017;154:398-406.e1.

3. Arsalan M, Squiers JJ, Herbert MA, et al. Comparison of Outcomes of Operative Therapy for Acute Type A Aortic Dissections Provided at High-Volume Versus LowVolume Medical Centers in North Texas. Am J Cardiol 2017;119:323-7.
Cite this article as: Kelly MO, Melby SJ. Surgeon experience impacts type A aortic dissection patient mortality. J Thorac Dis 2020;12(7):3897-3898. doi: 10.21037/jtd.2020.02.03 